\title{
e-interview
}

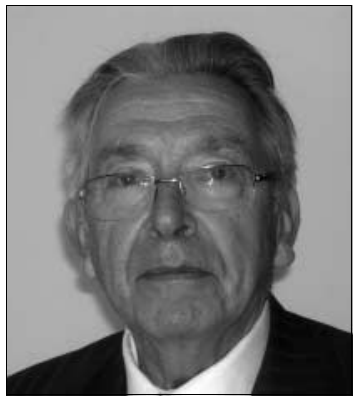

\section{Professor Sir David Goldberg}

David Goldberg is Professor Emeritus, Institute of Psychiatry, King's College London. He trained in Oxford, St Thomas's Hospital and the Maudsley Hospital. His special interests include services in lowand middle-income countries, social psychiatry, developing classification systems for mental health, and improving mental health aspects of general medical practice.

If you were not a psychiatrist, what would you do?

I'd be a clinical psychologist.

What has been the greatest impact of your profession on you personally? It has given me the opportunity to train a generation of future doctors.

Do you feel stigmatised by your profession?

Not one bit.

What are your interests outside of work?

Walking, talking, eating, cooking and playing with my grandchildren.

Who was your most influential trainer, and why?

Sir Aubrey Lewis, the professor for whom I worked. He was an intensely scholarly man with a grounding in the history of psychiatry.
What job gave you the most useful training experience?

Working for Dr Kraupl-Taylor at the

Maudsley helped me to tolerate people with very severe personality disorders.

\section{Which publication has influenced you} most?

Mainly novels - the only psychiatric book that made a deep impression on me was Institutionalism and Schizophrenia by J. K. Wing and G. W. Brown.

\section{How has the political environment} influenced your work?

In a fairly depressing way; for most of my life as a psychiatrist we had to keep a service running with almost constant reduction in budget - a gloomy scenario that may face us all again in the UK.

What part of your work gives you the most satisfaction?

It used to be teaching; it still is, I like that very much. I retired in 2000 and was running the Institute of Psychiatry at that time. It was totally absorbing.

\section{What do you least enjoy?}

Chairing committees.

What is the most promising opportunity facing the profession?

Rethinking the classification of mental disorders: it is an enormous opportunity to see if we couldn't do a better job.

\section{What is the greatest threat?}

An over-manned management, taking up the time of clinicians. Both political parties [in the UK] have a quasi-religious belief in management, more managers equaling a better and more efficient system.

What single change would substantially improve quality of care?

I think we do not set sufficiently clear, achievable targets for what should be accomplished during an in-patient admission. As a result, they may drift on rather aimlessly, achieving far less for the patient than they might.
What conflict of interest do you encounter most often?

None. From a World Health Organization perspective, if a drug company flies me to a conference, it is a conflict in their eyes but I would never talk about their drugs. Nonetheless, I have to limit these.

What is the most important advice you could offer to a new trainee?

Learn how to interview patients, and how not to. It is the fundamental thing we do. Then formulate that patient's problems with a written description of what they are, and what we should do about them. What we are up against is a checklist approach to psychiatry.

\section{Do you think psychiatry is brainless or} mindless?

Leon Eisenburg raised this question in a paper in the British Journal of Psychiatry in 1972: you can't be either. You've got to understand the brain, but you need to relate to people and their problems. You have to steer a middle ground.

What is the role of the psychiatrist in rebuilding healthcare systems?

In the UK, it's becoming quite a limited one. There are no longer full-time psychiatrists advising the Department of Health, and decisions are floating further away than ever from active clinicians. The College is still probably our best bet if future developments are not to damage the health system still further

What single area of psychiatric practice is most in need of development?

Teaching psychiatrists to do psychotherapy. It's not well taught. Also, getting psychiatrists to see that our task is to make people autonomous and independent of you, not dependent on the service.

How would you like to be remembered? I don't want to be remembered! Maybe as someone who helped my trainees and patients?

Dominic Fannon 